\title{
GERMINAÇÃO DE SEMENTES E CRESCIMENTO DE PLÂNTULAS DE CULTIVARES DE MILHO-PIPOCA SUBMETIDAS AO ESTRESSE HÍDRICO E SALINO ${ }^{1}$
}

\author{
LIAMARAMOTERLE², PABLO DE CARVALHOLOPES ${ }^{2}$, \\ ALESSANDRO DE LUCCAE BRACCINI ${ }^{3}$, CARLOSALBERTO SCAPIM ${ }^{3}$
}

\begin{abstract}
RESUMO - A disponibilidade hídrica e o movimento de água para as sementes são importantes para a germinação e emergência das plântulas, sendo estes fatores influenciados pelo potencial hídrico do solo, textura do solo e área de contato solo-semente. Sabendo que a salinidade limita o crescimento de muitas plantas, o objetivo desse trabalho foi avaliar o efeito do estresse hídrico e salino na germinação de sementes e no crescimento de plântulas de três cultivares de milho-pipoca (IAC 112, Zélia e BRS-Angela). As sementes foram semeadas em rolos de papel-toalha embebidos com soluções de cloreto de potássio $(\mathrm{KCl})$, utilizando-se cinco níveis de potencial osmótico: 0,0 (controle); - 0,$1 ;-0,3 ;-0,6$ e -0,9MPa. A qualidade fisiológica das sementes foi avaliada por meio da primeira contagem e da contagem final de germinação, do comprimento da raiz primária e da parte aérea das plântulas bem como da biomassa seca das plântulas. Os resultados indicam que a diminuição do potencial osmótico provoca redução no desempenho de sementes de milho-pipoca. Houve comportamento diferenciado das cultivares quanto à tolerância ao estresse provocado pelo $\mathrm{KCl}$. As sementes do cultivar BRS-Angela apresentam melhor germinação e crescimento de plântulas em relação às demais, quando submetidas aos mesmos níveis de potencial osmótico de $\mathrm{KCl}$.
\end{abstract}

Termos para indexação: Zea mays, salinidade, desempenho.

\section{GERMINATION OF SEEDS AND SEEDLING GROWTH OF POPCORNCULTIVARS UNDER WATER AND SALINITY STRESS}

\begin{abstract}
The water availability and the water movement though the seeds are very important to seed germination and seedlings emergence, and these factors are influenced by soil water potential, soil texture and soil-seed contact surface. Knowing that soil salinity limits the growth of several plants, the purpose of this study was to evaluate the effect of water and salinity stress on seed germination and seedling growth of three popcorn cultivars (IAC 112, Zélia e BRS-Angela). The seeds were sown in germination paper substrate imbibed in potassium chloride $(\mathrm{KCl})$ solutions using five levels of osmotic potential: 0.0 (control); $-0.1 ;-0.3 ;-0.6 \mathrm{e}-0.9 \mathrm{MPa}$. The percentage of normal seedlings at the first and final counting of the germination test, as well as root and shoot length and dry biomass of seedlings were used to evaluate seed physiological quality. The results indicated that the reduction of the osmotic potential reduced the popcorn seed performance. There was a differential behavior between the popcorn cultivars to the salinity stress tolerance promoted by the use of $\mathrm{KCl}$. The seeds of BRS-Angela cultivar showed better germination and seedling growth than the others, when submitted to the same level of $\mathrm{KCl}$ osmotic potential.

Index terms: Zea mays, salinity, performance.
\end{abstract}

\footnotetext{
${ }^{1}$ Submetido em 28/11/2005. Aceito para publicação em 05/09/2006. Parte da Dissertação de Mestrado da primeira autora apresentada à Universidade Estadual de Maringá (UEM);

${ }^{2}$ Eng. Agrônomo, pós-graduando do Programa de Pós-Graduação em
}

Agronomia, UEM - PR, lmoterle@hotmail.com.br;

${ }^{3}$ Eng. Agrônomo, Dr., Professor Associado, Departamento de Agronomia, Centro de Ciências Agrárias, UEM, Av. Colombo, 5790, CEP: 87020900, Maringá - PR, albraccini@uol.com.br, cascapim@uem.br. 


\section{INTRODUÇÃO}

O milho-pipoca, cultura típica do continente americano, é muito utilizado na alimentação humana e bastante apreciado no Brasil. Atualmente, os campos de produção de milhopipoca vêm aumentando gradativamente no país; isso se deve à maior demanda pelo produto in natura ou na forma de produtos industrializados. Nesse contexto, além da correta utilização das práticas culturais, o emprego de sementes com alta capacidade germinativa e elevado vigor é essencial para a emergência mais rápida e uniforme das plântulas sob ampla diversidade de condições ambientais, propiciando a obtenção de adequado estande de plantas no campo (Del Giúdice et al., 1998).

Pode-se inferir que, assim como as demais culturas, o milho-pipoca também está sujeito a condições adversas no campo, podendo apresentar fatores limitantes ao seu desenvolvimento. Aágua é um dos fatores que mais influencia o processo de germinação das sementes. Da absorção de água resulta a reidratação dos tecidos, com a conseqüente intensificação da respiração e de todas as demais atividades metabólicas que culminam com o fornecimento de energia e de nutrientes necessários para a retomada do crescimento do eixo embrionário (Carvalho e Nakagawa, 2000). Potenciais hídricos muitos negativos, especialmente no início da embebição, influenciam a absorção de água, podendo inviabilizar a seqüência dos eventos relacionados ao processo germinativo das sementes (Bansal et al., 1980).

O estresse hídrico geralmente atua diminuindo a velocidade e a porcentagem de germinação das sementes, sendo que para cada espécie existe um valor de potencial hídrico no solo, abaixo do qual a germinação não ocorre (Adegbuyi et al., 1981). A baixa disponibilidade de água causa redução no crescimento, ocasionada pela diminuição da expansão e do alongamento celular devido ao decréscimo da turgescência (Yasseen e Alomary, 1994). Por outro lado, Borges e Rena (1993) afirmam que o excesso de umidade geralmente provoca decréscimo na germinação, visto que impede a penetração do oxigênio e reduz todo o processo metabólico resultante.

Segundo Torres et al. (2000), nas regiões áridas e semiáridas, o excesso de sais no solo tem limitado a produção agrícola. A salinização do solo afeta negativamente a germinação, o estande das plantas, o desenvolvimento vegetativo das culturas, a produtividade e, nos casos mais graves, causa a morte das plântulas (Silva e Pruski, 1997). A alta concentração de sais é um fator de estresse para as plantas, pois reduz o potencial osmótico, retendo água, além da ação dos íons sobre o protoplasma. A água é osmoticamente retida em solução salina, de forma que o aumento da concentração de sais a torna cada vez menos disponível para as plantas (Ribeiro et al., 2001). Com o aumento da salinidade, ocorre a diminuição do potencial osmótico do solo, dificultando a absorção de água pelas raízes (Amorim et al., 2002).

A capacidade de adaptação dos vegetais superiores aos solos salinos depende de alguns fatores, destacando-se a constituição físiológica e o seu estádio de desenvolvimento (Brady, 1989). Algumas espécies, tais como sorgo, milho, feijão e trigo, são menos afetadas durante a fase inicial de seu ciclo (François et al., 1984; Maas et al., 1986). Porém, em arroz, a sensibilidade à salinização aumenta durante a floração e frutificação (Guerra, 1976).

O presente trabalho teve por objetivo avaliar o efeito do estresse hídrico e salino induzido por soluções de cloreto de potássio na germinação de sementes e no crescimento de plântulas de cultivares de milho-pipoca.

\section{MATERIAL E MÉTODOS}

O trabalho foi conduzido no Laboratório de Tecnologia de Sementes do Núcleo de Pesquisas Aplicadas à Agricultura, Universidade Estadual de Maringá. Foram utilizadas sementes comerciais de três cultivares de milho-pipoca: IAC 112 (híbrido simples modificado), Zélia (híbrido triplo) e BRS-Angela (variedade).

Soluções de cloreto de potássio $(\mathrm{KCl})$ foram utilizadas na obtenção do estresse salino e hídrico. Os níveis de potencial osmótico $(\mathrm{MPa})$ e as respectivas concentrações de $\mathrm{KCl}\left(\mathrm{g} . \mathrm{L}^{-1}\right)$ utilizadas foram: zero $(0,0) ;-0,1(1,673) ;-0,3(5,017) ;-0,6$ $(10,036)$ e $-0,9 \mathrm{MPa}(15,054 \mathrm{~g})$. Para o cálculo da quantidade de $\mathrm{KCl}$ a ser adicionada para a obtenção de cada tensão, utilizou-se a fórmula de Van't Hoff, citado por Salisbury e Ross (1991), ou seja: Yos = - RTC, em que: Yos = potencial osmótico $(\mathrm{atm}) ; \mathrm{R}=$ constante geral dos gases perfeitos $(0,082$ atm.mol. $\left.\mathrm{L}^{-1} \cdot \mathrm{K}^{-1}\right) ; \mathrm{T}=$ temperatura $(\mathrm{K}) ; \mathrm{C}=$ concentração $\left(\right.$ mol. $\left.\mathrm{L}^{-1}\right) ;$ mol. $\mathrm{L}^{-1} \mathrm{x}$ massa molar do $\mathrm{KCl}=\mathrm{g} . \mathrm{L}^{-1}$ e $\mathrm{T}(\mathrm{K})=$ $273+\mathrm{T}\left({ }^{\circ} \mathrm{C}\right)$.

A avaliação da germinação das sementes foi realizada pelo teste padrão de germinação, conduzido com quatro subamostras de 50 sementes para cada tratamento. As sementes foram semeadas entre três folhas de papel-toalha umedecidas com as soluções descritas anteriormente. Utilizou- 
se a quantidade de solução equivalente a 2,5 vezes a massa do papel seco. Em seguida, foram confeccionados rolos e estes colocados em germinador regulado para manter à temperatura de $25 \pm 2^{\circ} \mathrm{C}$. A avaliação foi realizada no sétimo dia após a instalação do teste, determinando-se a porcentagem de plântulas normais, conforme as Regras para Análise de Sementes (Brasil, 1992). A primeira contagem de germinação foi realizada no quarto dia após a semeadura, sendo utilizada a mesma metodologia descrita anteriormente para o teste de germinação (Brasil, 1992).

Para a avaliação do comprimento das plântulas, o substrato foi preparado da mesma maneira descrita para o teste de germinação, sendo utilizadas cinco subamostras de 20 sementes para cada tratamento. As sementes foram colocadas sobre duas folhas de papel de germinação, cobrindoas com outra folha e estas foram umedecidas com cada solução, com a micrópila voltada para a extremidade inferior do substrato. Em seguida, foram confeccionados rolos, os quais foram levados para germinador a de $25 \pm 2^{\circ} \mathrm{C}$, onde permaneceram por sete dias. O comprimento de raiz primária e parte aérea das plântulas consideradas normais foi avaliado no sétimo dia com auxilio de régua milimetrada, efetuando-se as medições em centímetros e os resultados foram expressos em cm.plântula ${ }^{-1}$ (Nakagawa, 1999).

A obtenção da biomassa seca das plântulas foi realizada após a avaliação do comprimento. As plântulas normais foram colocadas em sacos de papel devidamente identificadas e levadas para secar em estufa com circulação forçada de ar, regulada à temperatura de $80 \pm 2^{\circ} \mathrm{C}$, por um período de 24 horas. Em seguida, foi realizada a pesagem do material em balança analítica, obtendo-se, então, a biomassa seca com precisão de $0,001 \mathrm{~g}$ e o peso de cada amostra foi dividido pelo número de plântulas normais que foram utilizadas no teste para cada amostra, obtendo-se, então, a biomassa seca média de cada plântula (Nakagawa, 1999). Os resultados foram expressos em g.plântula ${ }^{-1}$.

Adotou-se o delineamento experimental inteiramente casualizado (D.I.C.), com quatro repetições para os testes de primeira contagem e contagem final da germinação e cinco repetições para os testes de comprimento de plântulas e biomassa seca. Os tratamentos foram arranjados no esquema fatorial 3x5 (cultivares de milho-pipoca x níveis de potencial osmótico). As médias foram comparadas pelo teste de Newman-Keuls para avaliação dos efeitos de cultivares e por análise de regressão para verificar o comportamento das variáveis em função dos níveis de potencial osmótico, para cada cultivar, em nível de $5 \%$ de probabilidade.

\section{RESULTADOS E DISCUSSÃO}

Os resultados da análise de variância revelaram efeitos significativos, $5 \%$ de probabilidade, para os efeitos principais cultivar e potencial osmótico, bem como para a interação, em todas as características avaliadas. Isso significa que as cultivares tiveram comportamento diferente em relação às concentrações salinas.

As médias da porcentagem de plântulas normais nos testes de germinação e primeira contagem da germinação, bem como do comprimento da raiz primária e da parte aérea das plântulas e da biomassa seca das plântulas, provenientes de três cultivares de milho-pipoca, em cada nível de potencial osmótico de $\mathrm{KCl}$, encontram-se na Tabela 1.

As sementes da cultivar BRS-Angela apresentaram maior porcentagem de germinação e de plântulas normais na primeira contagem do teste de germinação, em praticamente todos os níveis de potencial osmótico de $\mathrm{KCl}$ avaliados, em comparação as demais cultivares, exceto em $-0,1 \mathrm{MPa}$, no qual não houve diferença significativa entre BRS-Angela e IAC 112, e em $0,9 \mathrm{MPa}$, onde o valor de porcentagem de plântulas normais foi zero para todas as cultivares (Tabela 1).

Quanto à avaliação da biomassa seca das plântulas (Tabela 1), os resultados foram condizentes com aqueles observados na porcentagem de germinação e na primeira contagem de germinação, em que as sementes da cultivar BRS-Angela apresentaram superioridade em relação às das cultivares IAC 112 e Zélia, em todas as concentrações do sal. Nas demais características avaliadas, ou seja, comprimento da raiz primária e da parte aérea das plântulas, grande variabilidade nos resultados foi observada entre as sementes das diferentes cultivares. No que diz respeito ao comprimento da raiz primária, não houve diferença significativa entre as cultivares BRS-Angela e IAC 112 no nível zero (controle) e nos níveis de potencial osmótico -0,1 e -0,9MPa de $\mathrm{KCl}$. Nos níveis intermediários, as sementes de BRS-Angela apresentaram maior comprimento da radícula em $-0,3 \mathrm{MPa}$, enquanto que não houve diferença no comprimento da radícula das plântulas entre as cultivares de BRS-Angela e Zélia, no nível de potencial osmótico de -0,6MPa (Tabela 1).

Em relação ao comprimento da parte aérea das plântulas (Tabela 1), as plântulas da cultivar IAC 112 apresentaram os maiores valores no tratamento controle e nos níveis de potencial osmótico de $-0,1$ e $-0,3 \mathrm{MPa}$ de $\mathrm{KCl}$. Nas concentrações mais elevadas $(-0,6$ e $-0,9 \mathrm{MPa})$ não houve diferença no comprimento da parte aérea das plântulas entre as cultivares de milho-pipoca avaliadas. 
TABELA 1. Resultados médios da porcentagem de plântulas normais na primeira contagem e contagem final do teste de germinação, do comprimento da parte aérea e raiz primária das plântulas e da biomassa seca das plântulas, provenientes de três cultivares de milho-pipoca, submetidas a cinco níveis de potencial osmótico em solução de $\mathrm{KCl}$.

\begin{tabular}{|c|c|c|c|c|c|}
\hline \multirow{2}{*}{ Cultivares } & \multicolumn{5}{|c|}{ Potencial osmótico $\left(\mathrm{Mpa}^{1}\right)$} \\
\hline & 0,0 & $-0,1$ & $-0,3$ & $-0,6$ & $-0,9$ \\
\hline & \multicolumn{5}{|c|}{ Primeira contagem da germinação (\%) } \\
\hline IAC 112 & $66,5 \mathrm{~B}$ & $61,0 \mathrm{~A}$ & $19,5 \mathrm{~B}$ & $0 \mathrm{~B}$ & $0 \mathrm{~A}$ \\
\hline Zélia & $53,3 \mathrm{C}$ & $16,0 \mathrm{~B}$ & $0,5 \mathrm{C}$ & $0 \mathrm{~B}$ & $0 \mathrm{~A}$ \\
\hline \multirow[t]{2}{*}{ BRS-Angela } & $84,5 \mathrm{~A}$ & $54,5 \mathrm{~A}$ & $37,5 \mathrm{~A}$ & $17,0 \mathrm{~A}$ & $0 \mathrm{~A}$ \\
\hline & \multicolumn{5}{|c|}{ Germinação (\%) } \\
\hline IAC 112 & $77,5 \mathrm{~B}$ & $61,0 \mathrm{~A}$ & $36,0 \mathrm{~B}$ & $0 \mathrm{~B}$ & $0 \mathrm{~A}$ \\
\hline Zélia & $76,0 \mathrm{~B}$ & $32,0 \mathrm{~B}$ & $2,0 \mathrm{C}$ & $0 \mathrm{~B}$ & $0 \mathrm{~A}$ \\
\hline \multirow[t]{2}{*}{ BRS-Angela } & $89,0 \mathrm{~A}$ & $69,0 \mathrm{~A}$ & $49,0 \mathrm{~A}$ & $40,5 \mathrm{~A}$ & $0 \mathrm{~A}$ \\
\hline & \multicolumn{5}{|c|}{ Comprimento da raiz primária $(\mathrm{cm})$} \\
\hline IAC 112 & $23,9000 \mathrm{~A}$ & $20,206 \mathrm{~A}$ & $18,401 \mathrm{~B}$ & $4,800 \mathrm{~B}$ & $4,241 \mathrm{~A}$ \\
\hline Zélia & $22,1308 \mathrm{~B}$ & $16,235 \mathrm{~B}$ & $11,875 \mathrm{C}$ & $7,237 \mathrm{~A}$ & $2,152 \mathrm{~B}$ \\
\hline \multirow[t]{2}{*}{ BRS-Angela } & $23,7618 \mathrm{~A}$ & $21,454 \mathrm{~A}$ & $21,846 \mathrm{~A}$ & $8,552 \mathrm{~A}$ & $4,741 \mathrm{~A}$ \\
\hline & \multicolumn{5}{|c|}{ Comprimento da parte aérea $(\mathrm{cm})$} \\
\hline IAC 112 & $23,109 \mathrm{~A}$ & $22,524 \mathrm{~A}$ & $14,823 \mathrm{~A}$ & $3,049 \mathrm{~A}$ & $0,616 \mathrm{~A}$ \\
\hline Zélia & $20,979 \mathrm{~B}$ & $19,457 \mathrm{~B}$ & 7,698 C & $2,295 \mathrm{~A}$ & $0,000 \mathrm{~A}$ \\
\hline \multirow[t]{2}{*}{ BRS-Angela } & $20,431 \mathrm{~B}$ & $20,354 \mathrm{~B}$ & $12,774 \mathrm{~B}$ & $1,733 \mathrm{~A}$ & $1,550 \mathrm{~A}$ \\
\hline & \multicolumn{5}{|c|}{ Biomassa seca das plântulas (g) } \\
\hline IAC 112 & $0,0292 \mathrm{C}$ & $0,0286 \mathrm{~B}$ & $0,0238 \mathrm{~B}$ & $0,0104 \mathrm{~B}$ & $0,0112 \mathrm{~B}$ \\
\hline Zélia & $0,0372 \mathrm{~B}$ & $0,0266 \mathrm{~B}$ & $0,0132 \mathrm{C}$ & $0,0084 \mathrm{~B}$ & $0,0022 \mathrm{C}$ \\
\hline BRS-Angela & $0,0452 \mathrm{~A}$ & $0,0456 \mathrm{~A}$ & $0,0418 \mathrm{~A}$ & $0,0220 \mathrm{~A}$ & $0,0168 \mathrm{~A}$ \\
\hline
\end{tabular}

${ }^{1}$ Médias seguidas de letras maiúsculas na mesma coluna não diferem entre si, a 5\% de probabilidade, pelo teste de Newman-Keuls.

Nota-se que em praticamente todas as variáveis analisadas nas sementes e plântulas de milho-pipoca, submetidas às condições de estresse, a cultivar BRS-Angela apresentou desempenho superior às demais cultivares avaliadas. Isso pode ser explicado em razão da constituição genética da cultivar BRS-Angela que possui maior número de genótipos que a constitui; assim, apresenta base genética mais ampla e, portanto, maior plasticidade genética frente às variações ambientais (Allard, 1960; Pinto, 1995). Os híbridos de linhagens IAC 112 e Zélia, com base genética mais estreita, não toleraram os níveis de estresse mais elevados.

Outra questão relevante é que as cultivares que apresentam sementes de melhor qualidade fisiológica, geralmente, são também as que se apresentam mais tolerantes às condições de estresse hídrico no campo, conforme foi verificado por Piana e Silva (1998) e Tonin et al. (2000), trabalhando com sementes de milho, e Braccini et al. (1996; 1998), trabalhando com sementes de soja. Isso pode justificar o fato da cultivar que apresentou melhor qualidade fisiológica inicial (BRS-Angela), mostrar-se tolerante à condição de estresse.

O comportamento das variáveis, em função dos níveis de potencial osmótico de $\mathrm{KCl}$, para cada cultivar de milhopipoca, foi avaliado por meio de análise de regressão, conforme encontra-se ilustrado nas Figuras 1 e 2. Os resultados da porcentagem de plântulas normais na primeira contagem e na contagem final do teste de germinação estão ilustrados na Figura 1. Optou-se pela análise descritiva, com a representação dos desvios padrões, uma vez que os resultados obtidos não permitiram o ajuste de equações de regressão para essas duas características.

Observa-se na primeira contagem do teste de germinação (Figura 1A) que, embora tenha ocorrido redução na porcentagem de plântulas normais de todas as cultivares avaliadas com a redução do potencial osmótico em solução de $\mathrm{KCl}$, a cultivar BRS-Angela apresentou menor redução 


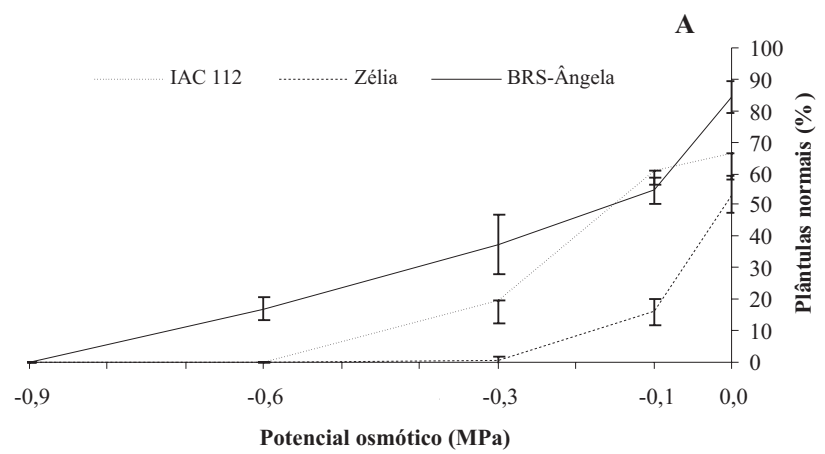

B

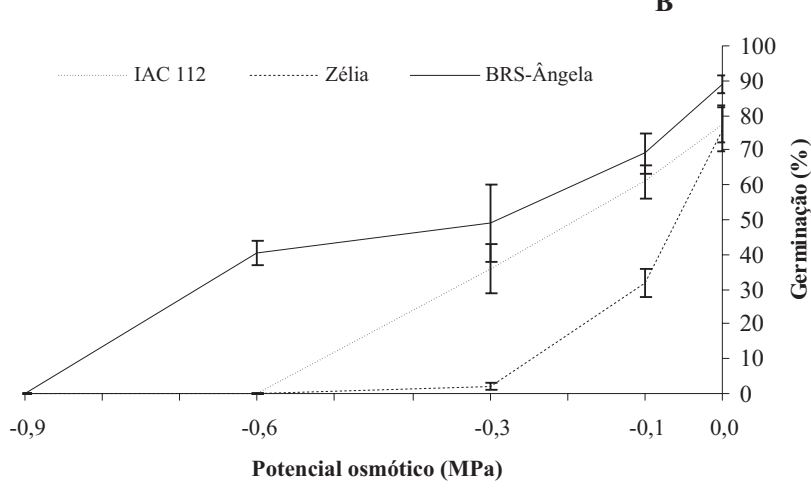

FIGURA 1. Porcentagem de plântulas normais na primeira contagem (A) e contagem final (B) do teste de germinação das sementes de três cultivares de milho-pipoca, submetidas a cinco níveis de potencial osmótico em solução de KCl.

média no vigor das sementes, avaliado por intermédio dessa característica.

Quanto à germinação das sementes (Figura 1B), houve redução na porcentagem de plântulas normais de todas as cultivares com o decréscimo nos níveis de potencial osmótico de $\mathrm{KCl}$, sendo a germinação totalmente inibida quando as sementes foram submetidas aos menores níveis de potencial osmótico da solução de $\mathrm{KCl}$ (Figura 1B). Isso indica o efeito negativo do estresse hídrico e salino sobre o desenvolvimento inicial das plântulas. Resultados semelhantes também foram relatados por Tonin et al. (2000), com sementes de milho, sob níveis de Polietileno Glicol e por Braccini et al. (1996), com sementes de soja, sob níveis de potencial osmótico de até $-0,9 \mathrm{MPa}$ de $\mathrm{NaCl}$, Manitol e Polietileno Glicol.

Do mesmo modo, Santos et al. (1992) observaram que a porcentagem de sementes não germinadas, nos tratamentos sob condições de estresse salino, foi muito elevada nos menores valores de potenciais osmóticos, sugerindo que os efeitos tóxicos dos sais provocaram inibição da germinação.

Esses resultados têm sido atribuídos à redução da quantidade de água absorvida pelas sementes em meio salino, com a redução do potencial osmótico das soluções (Braccini et al., 1996). Larcher (1986) relatou que o excesso de íons no solo, como o $\mathrm{Cl}^{-}$, tende a causar intumescência protoplasmática, afetando a atividade enzimática e resultando na produção inadequada de energia e distúrbios na assimilação de nitrogênio. Essa afirmativa pode explicar os resultados encontrados no presente estudo em relação ao decréscimo da germinação das sementes.

Os resultados de comprimento da raiz primária das plântulas das três cultivares de milho-pipoca estão apresentados na Figura 2A. Observou-se decréscimo linear no comprimento da raiz primária das plântulas de todas as cultivares avaliadas, com a redução dos níveis de potencial osmótico da solução. Contudo, novamente, as plântulas da cultivar BRS-Angela foram as que apresentaram menor redução na variável analisada com o decréscimo do potencial osmótico, em comparação com as plântulas das cultivares IAC 112 e Zélia, que apresentaram os piores resultados na referida avaliação. Santos et al. (1992), trabalhando com sementes de soja, observaram redução do crescimento das raízes, quando as sementes foram submetidas a condições de estresse.

Para os resultados de comprimento da parte aérea das plântulas (Figura 2B), à semelhança do que ocorreu para o teste de germinação e de primeira contagem da germinação (Figura 1A e B), bem como no comprimento da raiz primária das plântulas (Figura 2A), houve redução na referida característica à medida que o potencial osmótico da solução foi diminuído. Esses resultados estão coerentes com aqueles obtidos na avaliação das médias das cultivares, conforme observado na Tabela 1.

Em contrapartida, observa-se nos resultados da Figura 2B que, a cada uma unidade de variação no potencial osmótico, ou seja, 1,0MPa que reduz o potencial, ocorre decréscimo de $28,4 \mathrm{~cm}$ (coeficiente angular) no comprimento da parte aérea para a cultivar IAC $112 ; 24,7 \mathrm{~cm}$ para Zélia e $23,7 \mathrm{~cm}$ para BRS-Angela. Portanto, a cultivar IAC 112 apresentou maior redução média no comprimento da parte aérea das plântulas, enquanto que a menor foi constatada para a cultivar BRSAngela.

Segundo Dell'Áquilla (1992), a redução no comprimento das plântulas se deve às mudanças na turgescência celular, em função da diminuição da síntese de proteína nas condições de estresse hídrico. Taiz e Zeiger (2004) relatam que o primeiro efeito mensurável do estresse hídrico é a diminuição no crescimento, causada pela redução da expansão celular.

Nota-se, também, que a biomassa seca das plântulas das três cultivares de milho-pipoca decresceu com a redução dos 


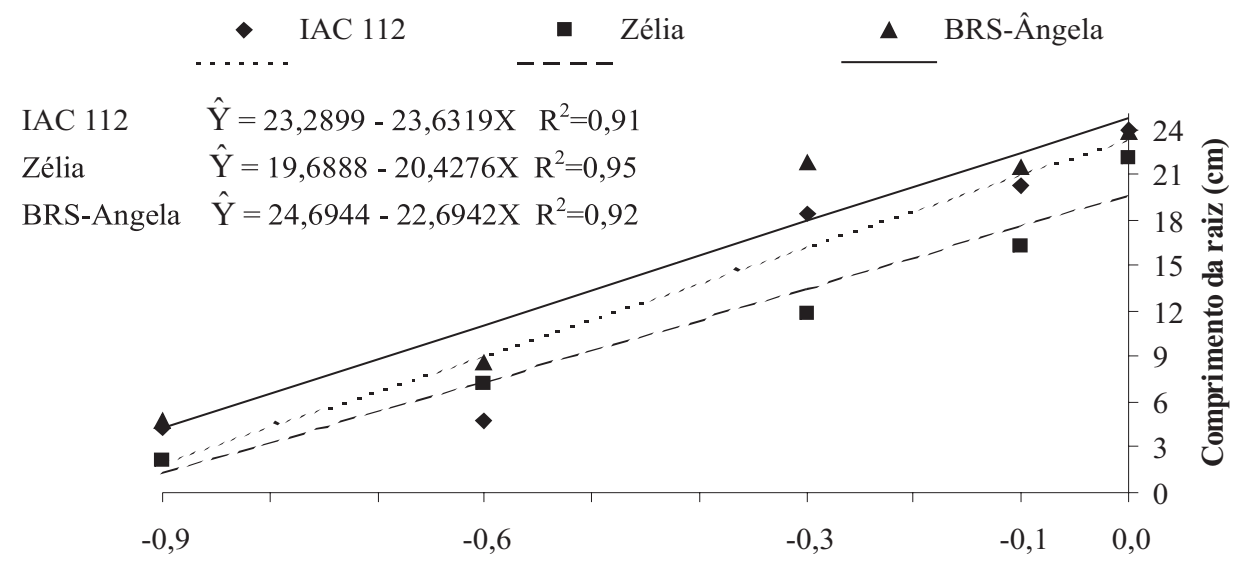

Potencial osmótico (MPa)

B

- IAC $112 \quad$ Z Zélia

- BRS-Ângela

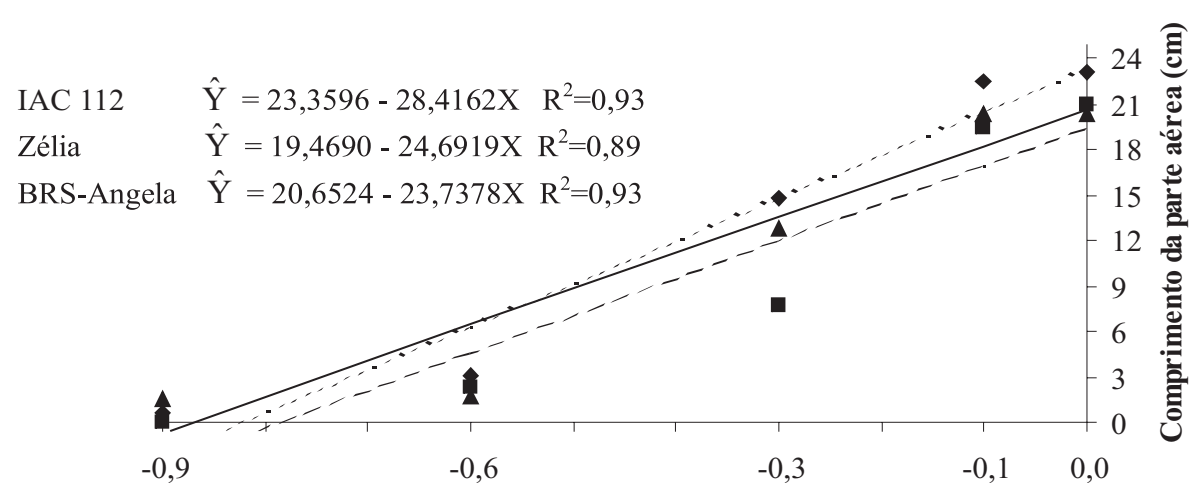

Potencial osmótico (MPa)

C

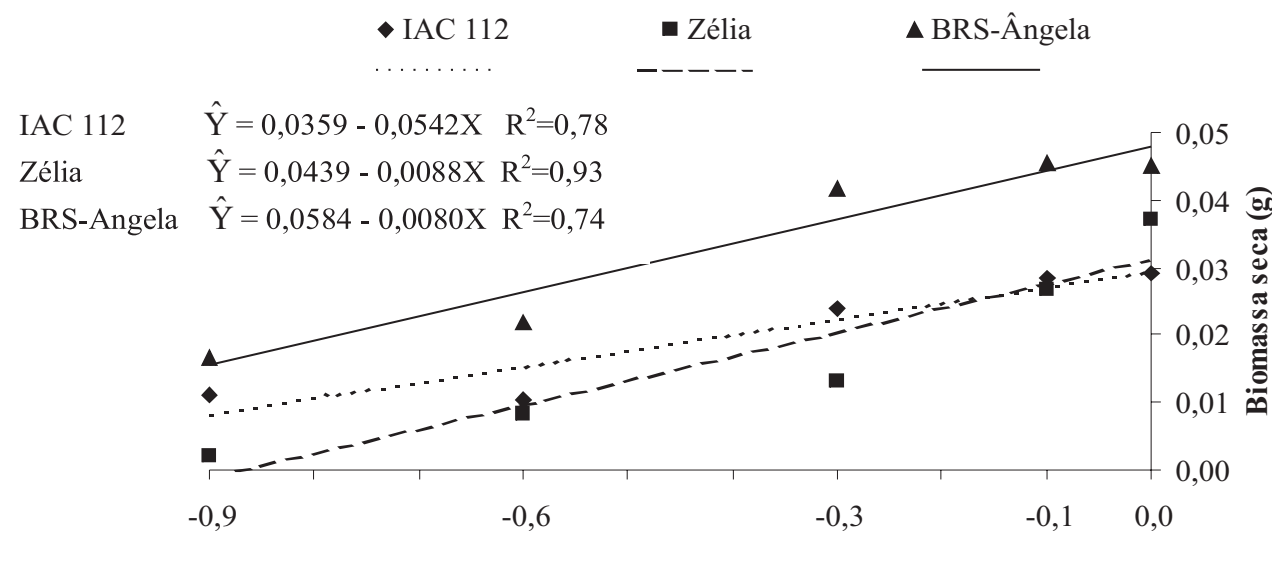

Potencial osmótico (MPa)

FIGURA 2. Comprimento (cm) da raiz primária (A), parte aérea (B) e biomassa seca - $\mathrm{g}(\mathrm{C})$ das plântulas de três cultivares de milhopipoca, submetidas a cinco níveis de potencial osmótico em solução de KCl. 
níveis de potencial osmótico, conforme ilustra a Figura 2C. Resultados semelhantes foram obtidos por Braccini et al. (1996) e Moraes e Menezes (2003), contudo, trabalhando com sementes de soja. Esta redução na biomassa seca, assim como no crescimento das plântulas, pode ser explicada pela diminuição no metabolismo das sementes, em função da menor disponibilidade de água para digestão das reservas e translocação de produtos metabolizados (Bewley e Black, 1994).

Comparando-se as três cultivares, em relação ao acúmulo de biomassa seca das plântulas, a cultivar que mais se destacou foi a BRS-Angela (Tabela 1), apresentando plântulas com maior biomassa seca em todos os níveis de potencial osmótico avaliados (Figura 2C).

Conforme pôde ser observado neste estudo, existem níveis de potencial osmótico que provocam redução no desempenho das sementes, tornando-se críticos para o desenvolvimento das plântulas. Os resultados revelam a importância da avaliação dos potenciais hídricos do substrato, considerados críticos para a germinação das sementes e estabelecimento das plântulas de milho-pipoca, além da necessidade de seleção criteriosa das cultivares que possam apresentar tolerância às condições de estresse ocasionadas pela salinidade do meio.

\section{CONCLUSÕES}

A diminuição do potencial osmótico provoca redução no desempenho de sementes de milho-pipoca.

Há comportamento diferenciado das cultivares quanto à tolerância à condição de estresse provocada pelo $\mathrm{KCl}$.

Sementes da cultivar BRS-Angela apresentam melhor germinação e crescimento de plântulas em relação às cultivares Zélia e IAC 112, quando submetidas a diferentes níveis de potencial osmótico de $\mathrm{KCl}$.

\section{REFERÊNCIAS}

ADEGBUYI, E.; COOPER, S.R.; DON, R. Osmotic priming of some herbage grass seed using polyethyleneglycol (PEG). Seed Science and Technology, Zürich, v.9, n.3, p.867-878, 1981.

ALLARD, R.W. Principles of plants breeding. New York: J. Willey \& Sons, 1960. 485p.

AMORIM, J.R.A.; FERNANDES, P.D.; GHEYI, H.R.; AZEVEDO, N.C. Efeito da salinidade e modo de aplicação da água de irrigação no crescimento e produção de alho. Pesquisa Agropecuária Brasileira, Brasília, v.37, n.2, p.167-176, 2002.

BANSAL, R.P.; BHATI, P.R.; SEN, D.N. Differential specificity in water inhibition of Indian arid zone. Biologia Plantarum, Praha, v.22, n.5, p.327-331, 1980 .

BEWLEY, J.; BLACK, M. Seeds: physiology of development and germination. 3. ed. New York: Plenum Press, 1994. 445p.

BORGES, E.E.L.; RENA, A.B. Germinação de sementes. In: AGUIAR, I.B.; PIÑA-RODRIGUEZ, F.C.M.; FIGLIOLIA, M.B. (Ed.) Sementes florestais tropicais. Brasília: ABRATES, 1993. p.83135.

BRACCINI, A.L.; RUIZ, H.A.; BRACCINI, M.C.L.; REIS, M.S. Germinação e vigor de sementes de soja sob estresse hídrico induzido por soluções de cloreto de sódio, manitol e polietileno glicol. Revista Brasileira de Sementes, Brasília, v.18, n.1, p.10$16,1996$.

BRACCINI, A.L.; REIS, M.S.; SEDIYAMA, C.S.; SEDIYAMA, T.; ROCHA, V.S. Influência do potencial hídrico induzido por polietilenoglicol na qualidade fisiológica de sementes de soja. Pesquisa Agropecuária Brasileira, Brasília, v.33, n.9, p.1451-1459, 1998.

BRADY, N.C. Natureza e propriedades dos solos. São Paulo: Freitas Bastos, 1989. 878p.

BRASIL. Ministério da Agricultura e da Reforma Agrária. Regras para análise de sementes. Brasília: SNDA/DNDV/CLAV, 1992. 365 p.

CARVAlho, N.M.; NAKAGAWA, J. Sementes: ciência, tecnologia e produção. 4.ed. Jaboticabal: FUNEP, 2000. 588p.

DELL'ÁQUILLA, A. Water uptake and protein synthesis in germinating wheat embryos under osmotic stress of polyetylene glycol. Annais of Botany, Camberra, v.69, n.2, p.167-171, 1992

DEL GIÚDICE, M.P.; REIS, M.S.; SEDIYAMA, T.; MOSQUIM, P.R. Avaliação da qualidade fisiológica de sementes de soja submetidas ao condicionamento osmótico em diferentes temperaturas. Revista Brasileira de Sementes, Brasília, v.20, n.2, p.245-262, 1998.

FRANCOIS, L.E.; DONOVANT, T.; MAAS, E.V. Salinity effect on seed yield, Griculth and germination in sorghum. Agronomy Journal, Madison, v.76, n.5, p.741-744, 1984.

GUERRA, H.O.C. Relações solo-água-planta. Campina Grande: UFPB, 1976. 136p.

LARCHER, W. Ecofisiologia vegetal. São Paulo: EPU, 1986. 319p.

MAAS, E.V.; FRANCOIS, L.E.; DONOVANT, T. ; YOUNJS, V.L. Effect salinity on grain yield and quality, vegetative growth, and germination of semi-awart and ourum wheat. Agronomy Journal, Madison, v.78, n.1, p.145-152, 1986.

MORAES, G.A.F.; MENEZES, N.L. Desempenho de sementes de soja sob condições diferentes de potencial osmótico. Ciência Rural, Santa Maria, v.33, n.2, p.219-226, 2003.

NAKAGAWA, J. Teste de vigor baseado no desempenho das plântulas. In: KRZYZAMOWSKI, F.C.; VIEIRA, R.D.; FRANÇA NETO, J.B. (ed.). Vigor de sementes: conceito e testes. Londrina: ABRATES, 1999. p.1-24.

PIANA, Z.; SILVA, W.R. Respostas de sementes de milho, com diferentes níveis de vigor, à disponibilidade hídrica. Pesquisa Agropecuária Brasileira, Brasília, v.33, n.9, p.1525-1531, 1998. 
PINTO, R.J.B. Introdução ao melhoramento genético de plantas. Maringá: EDUEM, 1995.275p.

RIBEIRO, M.C.C.; MARQUES, B.M.; AMARRO FILHO, J. Efeito da salinidade na germinação de sementes de quatro cultivares de girassol (Helianthus annuus L.). Revista Brasileira de Sementes, Brasília, v.23, n.1, p.281-284, 2001.

SALISBURY, F.B.; ROSS, C.W. Plant physiology. 4.ed. Belmont: Wadsworth, 1991. 682p.

SANTOS, V.L.M.; CALIL, A.C.; RUIZ, H.A.; ALVARENGA, E.M.; SANTOS, C.M. Efeito do estresse salino e hídrico na germinação e vigor de sementes de soja. Revista Brasileira de Sementes, Brasília, v.14, n.2, p.189-194, 1992.

SILVA, D.; PRUSKI, F.F. Recursos hídricos e desenvolvimento sustentável da agricultura. Brasília: MMA/ SBH/ABEAS, 1997.
$252 \mathrm{p}$.

TAIZ, E.; ZEIGER, L. Fisiologia vegetal. 3.ed. Porto Alegre: ARTMED, 2004. 719p.

TONIN, G.A.; CARVALHO, N.M.; KRONKA, S.N.; FERRAUDO, A.S. Influência do cultivar e do vigor no desempenho germinativo de sementes de milho em condições de estresse hídrico. Revista Brasileira de Sementes, Brasília, v.22, n.1, p.276-279, 2000.

TORRES, S.B.; VIEIRA, E.L.; MARCOS FILHO, J. Efeitos da salinidade na germinação e no desenvolvimento de plântulas de pepino. Revista Brasileira de Sementes, Brasília, v.22, n.2, p.3943, 2000.

YASSEEN, B.T.; ALOMARY, S.S. An analysis of the effects of water-stress on leaf growth and yield of 3 barley cultivars. Irrigation Science, New York, v.14, n.3, p.157-162, 1994. 